\title{
Türkiye'nin Tarım Bölgeleri Bazında Mekanizasyon Düzeyinin Yersel Değişim Haritalarının Oluşturulması ve Değerlendirilmesi
}

\author{
Tayfun KORUCU ${ }^{1 *}$, Ali AYBEK ${ }^{1}$, Fatih SIVRIKAYA ${ }^{2}$ \\ ${ }^{1}$ KSÜ, Ziraat Fakültesi, Biyosistem Mühendisliği Bölümü, Kahramanmaraş \\ ${ }^{2}$ KSÜ, Orman Fakültesi, Orman Mühendisliği Bölümü, Kahramanmaraş
}

Geliş (Received): 12.09.2015

Kabul (Accepted): 30.12.2015

\begin{abstract}
ÖZET: Tarımsal üretimde, mekanizasyon girdisi üretim verimliliği üzerinde önemli bir etkiye sahiptir. Bu nedenle işletmelerin makine parkı ve işletilmesi bilimsel esaslara dayalı olarak yapılmalıdır. Ulusal ölçekli planlamalar için tarımsal mekanizasyon düzeyi göstergelerinin mevcut verilerle değerlendirilmesi gerekmektedir. Bu çalışmada; TUIK verileri kullanılarak, 2008-2013 yıllarında Türkiye'nin Tarım Bölgeleri bazında ve genelinde tarımsal mekanizasyon düzeyi gösterge değerleri $\left(\mathrm{kW} \mathrm{ha}{ }^{-1}\right.$, traktör 1000 ha $^{-1}$, ha traktör ${ }^{-1}$, alet/makine traktör $\left.\mathrm{r}^{-1}, \mathrm{~kW}\right)$ belirlenmiş, yersel değişim haritaları oluşturulmuş ve değerlendirilmiştir. Türkiye'nin tarımsal mekanizasyon düzeyi, hem genel hem de bölgelere göre, ele alınan yıllar itibariyle genel olarak artmıştır. $\mathrm{kW} \mathrm{ha}^{-1}$ gösterge değeri; en yüksek Marmara (6.91) en düşük Doğu Karadeniz Bölgesinde (0.35) belirlenmiştir. Türkiye'nin genel ortalaması ise 1.98-2.37 kW ha ${ }^{-1}$ olarak saptanmıştır. Traktör 1000 ha $^{-1}$ gösterge değeri; en yüksek Marmara Bölgesinde (91.69), en düşük Doğu Karadeniz Bölgesinde (11.12) belirlenmiştir. Türkiye genel ortalaması ise 44.02-52.23 traktör 1000 ha $^{-1}$ olarak saptanmıştır. ha traktör ${ }^{-1}$ gösterge değeri; Marmara bölgesinde 10.9, Doğu Karadeniz Bölgesinde 54, Türkiye genelinde ise ortalama 19.15 olarak belirlenmiştir. Alet/makina traktör ${ }^{-1}$ gösterge değerleri, en yüksek Doğu Karadeniz Bölgesinde (28.66), en düşük Batı Karadeniz Bölgesinde (5.55) olarak saptanmıştır. Türkiye genelinde ise 7.22-7.68 alet/makina traktör ${ }^{-1}$ değerleri belirlenmiştir. $\mathrm{kW}$ gösterge değeri; en yüksek Marmara Bölgesinde (74-75 kW), en düşük Doğu Karadeniz Bölgesinde (23-32 kW) belirlenmiştir. Türkiye genelinde ise 44-45 kW olarak saptanmıştır. 2008-2013 yılı verilerine göre, Türkiye'nin mekanizasyon düzeyinin istenilen ölçüde olmadığı görülmektedir. Tarımsal mekanizasyon seviyesinin iyileştirilebilmesi için bölgelerimize uygun tarımsal mekanizasyon planlamalarının yapılması, ortak makine parklarının oluşturulması ve ayrıca işletmelerin küçük işletmeler halinde oluşmasını önleyecek gerekli kanuni düzenlemelerin yapılması gereklidir.
\end{abstract}

Anahtar Kelimeler: Tarımsal mekanizasyon düzeyi, yersel haritalama, Türkiye tarım bölgeleri

\section{Development of Spatial Maps and Evaluation of the Agricultural Mechanization Level of the Turkish Agricultural Regions}

\begin{abstract}
In agricultural production, mechanization has a significant effect on the efficiency of output. To this respect, the equipment pools of farms and their management need to be established in accordance with scientific principles. Agricultural mechanization level indicators on a national scale scheduling must be evaluated with the present data. In this study, using data from TUIK (Turkish Statistical Institute) for the years 2008-2013, indicators of agricultural mechanization level $\left(\mathrm{kW} \mathrm{ha}{ }^{-1}\right.$, tractors $1000 \mathrm{ha}^{-1}$, ha tractor ${ }^{-1}$, equipment-machine tractor $\left.{ }^{-1}, \mathrm{~kW}\right) \mathrm{have}$ been summarized for the Turkish Agricultural Regions and for the country as a whole. Spatial maps of change have been established and evaluated. In the considered years, the agricultural mechanization level of Turkey has risen by and large both throughout and in the regions of the country. The tractor power per unit of cultivated land was highest in Marmara Region $\left(6.91 \mathrm{~kW} \mathrm{ha}^{-1}\right)$ and lowest in the Eastern Black Sea Region $\left(0.35 \mathrm{~kW} \mathrm{ha}^{-1}\right)$. Across years, the average figure in Turkey was $1.98-2.37 \mathrm{~kW} \mathrm{ha}^{-1}$. The highest and lowest values for number of tractors per unit of 1000 ha cultivated land were respectively in the Marmara Region with 91.69 tractors 1000 ha $^{-1}$ and in the Eastern Black Sea Region with 11.12 tractors $1000 \mathrm{ha}^{-1}$. The overall average figure in Turkey is also 44.02-52.23 tractors $1000 \mathrm{ha}^{-1}$. The amount of cultivated land per tractor was 10.9 ha tractor $^{-1}$ in the Marmara Region, 54 ha tractor $^{-1}$ in the Black Sea Region and 19.15 ha tractor ${ }^{-1}$ across Turkey. The quantity of equipment per each tractor (equipmentmachine tractor $^{-1}$ ) ranked the highest in the Eastern Black Sea Region (28.66) and the lowest in the Western Black Sea Region (5.55). Across years, the overall average figure for Turkey was 7.22-7.68 equipment-machine tractor ${ }^{-1}$. The highest value of mean tractor power was in the Marmara Region (74-75 kW) and the lowest in the Eastern Black Sea Region (23-32 kW). Across years, the overall average figure for Turkey was 44-45 kW. It can be clearly seen that the agricultural mechanization level of Turkey was not at a desired level according to the data from TUIK for the years 2008-2013. The planning of appropriate agricultural mechanization, the creation of multi-farm use of machinery and limiting decreases in farm size are required to increase the the agricultural mechanization level of Turkey.
\end{abstract}

Key Words: Agricultural mechanization level, spatial map, Turkey agriculture regions

*Sorumlu yazar: Korucu, T., tkorucu@ksu.edu.tr 


\section{GİRIS}

Tarım sektörü, Türkiye ve $\mathrm{AB}$ ülkelerinin de dahil olduğu birçok ülkede; beslenme gereksinimini karşılaması, tarıma dayalı sanayinin hammadde kaynağını oluşturması, istihdam olanağı sağlaması, alanına yönelik dışa bağımlılığı önlemesi, ödemeler dengesi üzerinde etkilerinin olmasi nedeniyle ekonomide önemliliğini sürdürmektedir (Say et al. 2010).

Türkiye'de genel olarak tarımsal üretim, bitkisel ve hayvansal üretimin organik bir bütün olarak gerçekleştirildiği tarım işletmeleri tarafından yapılmaktadır. Tarım işletmeleri, teknik olarak önemli gelişmeler sağlamışlarsa da, gelişmiş ülkelerdeki tarım işletmelerinin gösterdikleri gelişmelere henüz ulaşamamışlardır.

Tarımsal faaliyetlerin kaliteli ve optimum bir şekilde yürütülebilmesi için bir takım girdilerin kullanılması kaçınılmazdır. $\mathrm{Bu}$ girdilerin en önemlilerinden birisi de üretimde modern tarım makinelerinin kullanılması yani tarımsal mekanizasyondur. Tarımsal mekanizasyon, ileri teknolojilerin uygulanmasını, ayrıca toprak, su, gübre, ilaç ve benzeri girdilerin etkin kullanımını olanaklı k1larak tarımda verimliliği sağlayan önemli bir üretim aracıdır. Gelişmiş ülkelerin tarımda, verimlilikte sağladığı gelişmelerin tümünde, mekanizasyon anahtar rol oynamıştır. Küresel rekabet ortamında bu rol kuşkusuz giderek artan önemle sürecektir (Evcim et al. 2010).

Tarımsal mekanizasyon; tarımsal üretim içerisinde toprak hazırlığından ürün hasadına kadarki dönemde, toplam tarımsal üretim girdilerinin yaklaşık \%40-50'sini oluşturmaktadır (Ruiyin et al. 1999; Landers, 2000). Bu durum modern işletmecilik ve optimum girdi kullanımı konularının önemini artırmaktadır. Tarımsal girdiler içinde önemli bir yer oluşturan mekanizasyon yatırımlarının planlı ve doğru bir şekilde yapılabilmesi için, işletmelerin tarımsal yapısının ve mekanizasyon özelliklerinin bilinmesi gereklidir (Akıncı et al. 1997). Tarımda makine kullanımı, teknolojik uygulamaların etkinliğini ve ekonomikliğini artırmakta ve çalışma koşullarını iyileştirmektedir. Tarım işletmelerinde kullanılan makineler; kapasite, güç, sayı, boyut, traktörmakine uyumu gibi özelliklerin yanında, işletmenin arazi varlığı, parsel büyüklüğü, toprak yapısı, ürün deseni, üretim teknikleri ve benzeri özelliklere bağlı olarak da verimliliği etkilerler.

Tarım işletmelerinin toplam verimliliği üzerinde mekanizasyon uygulamalarının etkisi, işletmelerin faaliyetlerini istenen düzeyde sürdürebilmeleri için, her üretim sezonu sonunda mutlaka bilimsel esaslara dayalı olarak değerlendirilmelidir. Bunun temel amacı gerek aynı bölge sinırlarında gerekse farklı ülkelerde benzer üretim koşullarında üretim yapan işletmelerin mekanizasyon uygulama yoğunlukları ve etkinlikleri açısından karşılaştırılmalarına olanak sağlamasıdır (Say et al. 2010).

Tarımda mekanizasyon işlemleri, büyük oranda traktör+tarım iş makinaları ile gerçekleştirilir. $\mathrm{Bu}$ nedenle tarım işletmelerinin veya ülkelerin tarımsal mekanizasyon düzeyinin belirlenmesinde ve karşılaştırılmasında;

- işlenen alana düşen traktör gücü $\left(\mathrm{kW} \mathrm{ha}^{-1}\right)$

- 1000 ha işlenen alana düşen traktör sayısı (traktör $1000 \mathrm{ha}^{-1}$ )

- traktör başına işlenen alan (ha traktör ${ }^{-1}$ )

- traktör başına alet/makine sayısı (alet/makine traktör $\left.{ }^{-1}\right)$ ve

- ortalama traktör gücü $(\mathrm{kW})$ gibi göstergeler dikkate alınmaktadır (Sabancı ve Akıncı 1994; Zeren et a.l 1995; Anonim, 2000; Ergüneș et al. 2009).

$\mathrm{Bu}$ çalışmada, 2014 TUIK verileri kullanılarak; 2008-2013 yıllarına ait Türkiye'nin tarım bölgeleri bazında;

$\checkmark$ Tarımsal mekanizasyon düzeylerinin belirlenmesi,

$\checkmark$ Bu düzeylerin yersel değişim haritalarının ve gruplarının oluşturulması,

$\checkmark$ Elde edilen sonuçların karşılaştırılması ve

$\checkmark$ Bu alanda bir veri tabanı oluşturulması amaçlanmıştır.

\section{MATERYAL ve YÖNTEM}

\section{Materyal}

Türkiye'nin on tarım bölgesine (Şekil 1) ilişkin tarımsal mekanizasyon düzeylerinin belirlenmesinde, istatistiksel kaynaklar ve veriler kullanılmıștır. Rakamsal olan bu değerler Türkiye İstatistik Kurumunun veri tabanındaki "Bitkisel Üretim İstatistikleri" ve "Tarımsal Alet ve Makina Sayıları" sekmeleri kullanılarak elde edilmiştir (TUIK, 2014). 2008-2013 y1llarına ait olan bu veriler; üretim alanları, traktör ile çekilen tarım alet/makine sayıları, traktör sayıları ve güçleridir. Buna göre Türkiye'nin tarım bölgelerine göre belirlenen toplam; tarım alanları, tarım alet ve makina sayıları, traktör sayıları ve traktör güçleri değerleri sırası ile Çizelge 1-4'de verilmiştir. 




Şekil 1. Türkiye'nin tarım bölgeleri haritası

Çizelge 1. Türkiye'nin tarım bölgelerine göre 2008-2013 yıllarına ait üretim alanları (ha) (TUIK, 2014)

\begin{tabular}{lrrrrrr}
\hline Tarım bölgesi & \multicolumn{7}{c}{ Üretim alanı (ha) } \\
\cline { 2 - 7 } (Agricultural regions) & \multicolumn{1}{c}{2008} & \multicolumn{1}{c}{2009} & 2010 & \multicolumn{1}{c}{2011} & \multicolumn{1}{c}{2012} & \multicolumn{1}{c}{2013} \\
\hline Akdeniz & 2441093 & 2419732 & 2464804 & 2388102 & 2317994 & 2341965 \\
Ege & 2893222 & 2791944 & 2839762 & 2752325 & 2799936 & 2813464 \\
Marmara & 3188756 & 3103742 & 3043020 & 2980718 & 2970600 & 2794424 \\
Batı Anadolu & 3601668 & 3566958 & 3497305 & 3371267 & 3380216 & 3443227 \\
Batı Karadeniz & 2158901 & 2113112 & 2126391 & 2058558 & 2087467 & 2051766 \\
Doğu Karadeniz & 677492 & 507220 & 664494 & 699383 & 702782 & 676046 \\
Orta Anadolu & 3539012 & 3938804 & 3993439 & 3788079 & 3786029 & 3686702 \\
Kuzey Doğu Anadolu & 1459495 & 1326283 & 1263876 & 1286520 & 1484857 & 1299287 \\
Orta Doğu Anadolu & 1377528 & 1259321 & 1288807 & 1260475 & 1271425 & 1298878 \\
Güney Doğu Anadolu & 3070187 & 2855073 & 3212307 & 3028334 & 2980693 & 2827163 \\
\hline Türkiye & 24407354 & 23882190 & 24394205 & 23613761 & 23781999 & 23232921 \\
\hline
\end{tabular}

Çizelge 2. Türkiye'nin tarım bölgelerine göre 2008-2013 yıllarına ait tarım alet/makina sayıları (TUIK, 2014)

\begin{tabular}{lrrrrrr}
\hline & \multicolumn{5}{c}{ Tarım alet/makina sayısı (adet) } \\
\cline { 2 - 7 } Tarım bölgesi & \multicolumn{1}{c}{2008} & 2009 & 2010 & \multicolumn{1}{c}{2011} & \multicolumn{1}{c}{2012} & 2013 \\
\hline Akdeniz & 617513 & 597006 & 661206 & 656950 & 709045 & 716337 \\
Ege & 1167440 & 1175493 & 1186115 & 1197719 & 1129821 & 1228915 \\
Marmara & 1323714 & 1325673 & 1353147 & 761034 & 1368156 & 1366759 \\
Batı Anadolu & 555903 & 576468 & 596346 & 605013 & 620478 & 620441 \\
Batı Karadeniz & 673957 & 680329 & 696430 & 716161 & 716145 & 725339 \\
Doğu Karadeniz & 81972 & 83380 & 84608 & 94547 & 93356 & 98115 \\
Orta Anadolu & 618909 & 636031 & 650522 & 660197 & 669618 & 675998 \\
Kuzey Doğu Anadolu & 187617 & 185082 & 193580 & 203507 & 207873 & 216331 \\
Orta Doğu Anadolu & 171015 & 171802 & 173754 & 177608 & 181529 & 185653 \\
Güney Doğu Anadolu & 270787 & 275184 & 304444 & 315207 & 337119 & 342770 \\
\hline Türkiye & 5668827 & 5706448 & 5900152 & 5387943 & 6033140 & 6176658 \\
\hline
\end{tabular}


Çizelge 3. Türkiye'nin tarım bölgelerine göre 2008-2013 yıllarına ait traktör sayıları (TUIK, 2014)

\begin{tabular}{|c|c|c|c|c|c|c|}
\hline \multirow[b]{2}{*}{ Tarım bölgesi } & \multicolumn{6}{|c|}{ Traktör sayısı (adet) } \\
\hline & 2008 & 2009 & 2010 & 2011 & 2012 & 2013 \\
\hline Akdeniz & 129398 & 128106 & 131949 & 136521 & 148262 & 151468 \\
\hline Ege & 225589 & 226971 & 230698 & 234462 & 247565 & 252014 \\
\hline Marmara & 238455 & 237804 & 241416 & 245446 & 254473 & 256211 \\
\hline Batı Anadolu & 91231 & 92381 & 93823 & 94866 & 94375 & 108325 \\
\hline Bat1 Karadeniz & 146279 & 147895 & 149728 & 156018 & 164353 & 171048 \\
\hline Doğu Karadeniz & 10466 & 6465 & 7389 & 9697 & 10466 & 12335 \\
\hline Orta Anadolu & 119138 & 118015 & 118791 & 121752 & 124340 & 122618 \\
\hline Kuzey Doğu Anadolu & 33974 & 33831 & 35352 & 37395 & 38193 & 39781 \\
\hline Orta Doğu Anadolu & 27865 & 28040 & 30307 & 31671 & 32935 & 35764 \\
\hline Güney Doğu Anadolu & 52134 & 53521 & 56068 & 56967 & 63087 & 63810 \\
\hline Türkiye & 1074529 & 1073029 & 1095521 & 1124795 & 1178049 & 1213374 \\
\hline
\end{tabular}

Çizelge 4. Türkiye'nin tarım bölgelerine göre 2008-2013 yıllarına ait toplam traktör güçleri (kW) (TUIK, 2014)

\begin{tabular}{lrrrrrr}
\hline & \multicolumn{5}{c}{ Toplam traktör güçü $(\mathrm{kW})$} \\
\cline { 2 - 7 } Tarım bölgesi & \multicolumn{1}{c}{2008} & \multicolumn{1}{c}{2009} & \multicolumn{1}{c}{2010} & \multicolumn{1}{c}{ (11 } & \multicolumn{1}{c}{2012} & \multicolumn{1}{c}{2013} \\
\hline Akdeniz & 4596952 & 4551777 & 4668742 & 4805250 & 5306757 & 5434909 \\
Ege & 7877565 & 7982129 & 8123618 & 8232459 & 8718691 & 8914905 \\
Marmara & 17773854 & 17684374 & 18037990 & 18288290 & 19017636 & 19303450 \\
Batı Anadolu & 3674012 & 3745274 & 3803834 & 3847204 & 3874906 & 4558395 \\
Bat1 Karadeniz & 5095371 & 5184210 & 5270876 & 5409480 & 5697997 & 6033276 \\
Doğu Karadeniz & 255234 & 205335 & 230819 & 248691 & 255234 & 287047 \\
Orta Anadolu & 4600908 & 4564115 & 4617697 & 4721348 & 4842666 & 4817480 \\
Kuzey Doğu Anadolu & 1415722 & 1424161 & 1509629 & 1591143 & 1629466 & 1702873 \\
Orta Doğu Anadolu & 1003153 & 1004152 & 1147517 & 1186960 & 1229341 & 1353287 \\
Güney Doğu Anadolu & 2124249 & 2127221 & 2237569 & 2270346 & 1229341 & 2555161 \\
\hline Türkiye & 48417020 & 48472748 & 49648293 & 50601172 & 51802035 & 54960783 \\
\hline
\end{tabular}

Çizelge 5. Hesaplamalarda kullanılan tarım alet/makina isimleri

\begin{tabular}{ll}
\hline Ara çapa makinesi & Motorlu tırpan \\
Balya makinesi & Orak makinesi \\
Biçerbağlar makinesi & Pulluklar \\
Dipkazan & Rototiller \\
Ekim ve Dikim Makinaları & Sap parçalama makinesi \\
Gübre dağıtma makinesi & Sap toplamalı saman yapma makinesi \\
Hasat ve Harman makineleri & Su tankeri (Tarımda kullanılan) \\
İlaçlama makinaları & Tarım arabası (Römork) \\
Kültüvatör & Taş toplama makinesi \\
Merdane & Tirmıklar \\
Silaj makineleri & Toprak tesviye makineleri \\
\hline
\end{tabular}

Tarım alanları belirlenirken ekili alanlar ve nadas alanlarının toplamları dikkate alınmıştır. Tarım alet ve makina sayıları belirlenirken Çizelge 5'de verilen ve traktörle çalıştırılan alet ve makinalar dikkate alınmıştır. $\mathrm{Bu}$ çizelgede verilen tarım alet ve makinalarının isimleri ana başlıklar altında toplanmıştır. Her grup altında farklı tarım alet ve makine isimleri de bulunmaktadır. Traktör sayıları belirlenirken sadece tekerlekli traktörler dikkate alınmış, paletli traktör sayıları hesaplamalarda kullanılmamıştır. Öncelikle traktörler tek akslı ve çift akslı olarak gruplandırılmış sonrasında her grup içerisinde de güç değerleri dikkate alınarak sınıflandırmalar yapılmıştır (Çizelge 6). Buna bağlı olarak her gruptaki traktör sayısı belirlenmiş ve bu değerler toplanarak o yıla ait veriler belirlenmiştir.
Cizelge 6. Traktör güç hesaplamasında kullanılan ortalama güç değerleri

\begin{tabular}{lc}
\hline Traktör grubu & Ortalama güç (BG) \\
\hline Tek akslı (1-5 BG) & 3.0 \\
Tek akslı (5 BG'den fazla) & 7.5 \\
İki akslı (1-10 BG) & 5.5 \\
İki akslı (11-24 BG) & 17.5 \\
İki akslı (25-34 BG) & 29.5 \\
İki akslı (35-50 BG) & 42.5 \\
İki akslı (51-70 BG) & 60.5 \\
İki akslı (70 BG'den fazla) & 85.0 \\
\hline
\end{tabular}

Çizelge 6'da verilen değerler BG birimi olarak verilmiştir. Hesaplamalar yapılırken bu birim kW'a dönüştürülmüştür. Toplam traktör gücü 
hesaplamalarında ise her grupta bulunan traktör sayısı o gruba ait ortalama traktör gücü ile çarpılmış ve elde edilen değer toplanarak o ylla ait toplam traktör gücü değeri $\mathrm{kW}$ cinsinden belirlenmiştir.

\section{Yöntem}

Tarımsal mekanizasyon düzeyi göstergelerine ait veriler elde edilirken materyal bölümünde verilen ilgili çizelgelerdeki değerler kullanılmıştır. Veri aralıklarını oluşturabilmek için ilk olarak en küçük ve en büyük veri değerleri arasındaki fark belirlenmiştir. Elde edilen değer beşe (grup sayıs1 - 1) bölünmüş ve bu değerin yarısı " \pm " olarak en küçük değere eklenmiș ve çıkartılmıştır. Böylece her mekanizasyon düzeyi gösterge değeri kendi içerisinde altı gruba ayrılmıştır. Örnegin; herhangi bir mekanizasyon gösterge ifadesinin en küçük değerini 5 ve en büyük değerini ise 10 olarak kabul edelim. Her iki değer arasındaki fark 5 olup bu değerin altı gruba ayrılabilmesi için 5 e bölünmesinden elde edilen değer de 1`dir. Bu değerin yarısı da 0.5 olarak bulunur. Buna göre gruplar; en küçük değer $\geq \mathrm{x} \leq$ $5.49 ; 5.5 \geq \mathrm{x} \leq 6.49 ; 6.5 \geq \mathrm{x} \leq 7.49 ; 7.5 \geq \mathrm{x} \leq 8.49 ; 8.5$ $\geq \mathrm{x} \leq 9.49 ; 9.5 \geq \mathrm{x} \leq$ en büyük değer şeklinde oluş̧urulur. Haritalar bu gruplar dikkate alınarak oluşturulmuştur. Elde edilen değerlerin bir kısmında en düşük ve en büyük değerlerde farklılıklar oluşmuştur. $\mathrm{Bu}$ nedenle bazı haritalar oluşturulurken en düşük değer ve en büyük değer göstergelerinde değişiklikler yapılmıştır. Elde edilen gruplar haritalar üzerinde verilmiştir.

Birim alana düșen traktör gücü $\left(k W h a^{-1}\right)$; toplam traktör gücü toplam tarımsal alana oranlanmıștır. 1000 ha alana düşen traktör saylsı (traktör $1000 \mathrm{ha}^{-1}$ ); toplam tarım alanı 1000 ha'a oranlanmıs daha sonra elde edilen değer toplam traktör sayısına oranlanmıștır. Traktör başına düșen tarım alanı (ha traktör ${ }^{-1}$ ); toplam tarım alanı toplam traktör sayısına oranlanmıştır. Traktör başına düşen alet/makina sayısı (alet/makine traktör $\left.r^{-1}\right)$; toplam alet/makina sayıs1 toplam traktör sayısına oranlanmıştır. Ortalama traktör gücü $(\mathrm{kW})$ ise; toplam traktör gücünün toplam traktör sayısına oranlanması ile elde edilmiștir. Hesaplamalar sonucunda belirlenen tarımsal mekanizasyon düzeyi gösterge değerlerinin sınır değerleri Çizelge 7'de verilmiştir.

Çizelge 7. Belirlenen tarımsal mekanizasyon düzeyi gösterge değerlerinin sınır değerleri

\begin{tabular}{|c|c|}
\hline Tarımsal mekanizasyon düzeyi göstergesi & Sinır değerler \\
\hline Birim alana düşen traktör gücü $\left(\mathrm{kW} \mathrm{ha}^{-1}\right)$ & $0.35-6.91$ \\
\hline 1000 ha alana düşen traktör sayısı (traktör $1000 \mathrm{ha}^{-1}$ ) & $11.12-91.69$ \\
\hline Traktör başına düşen tarım alanı (ha traktör ${ }^{-1}$ ) & $10.91-89.93$ \\
\hline Traktör başına düşen alet/makine sayısı (alet/makina traktör ${ }^{-1}$ ) & $3.10-12.90$ \\
\hline Ortalama traktör gücü $(\mathrm{kW})$ & $23.27-75.34$ \\
\hline
\end{tabular}

Türkiye'nin on tarım bölgesine ait tarımsal mekanizasyon düzeyi haritaları, ArcGIS 10.1TM yazılımında RMS (Root Mean Square) hatas1 3 metreden az olacak şekilde koordinatlandırılmıştır. Elde edilen görüntü üzerinde $1 / 3000-1 / 5000$ ölçek hassasiyetinde çalışılarak bilgisayar ekranında haritalar sayısal ortamda oluşturulmuştur. Türkiye'ye ait öznitelik veri Tablesuna gerekli bilgiler $\left(\mathrm{kW} \mathrm{ha}^{-1}\right.$, traktör 1000 ha $^{-1}$, ha traktör ${ }^{-1}$, alet/makina traktör ${ }^{-1}$ ve $\mathrm{kW})$ girilmiștir. ArcMap ortamında Reclassify komutu kullanılarak Türkiye için "birim alana düşen traktör gücü”, "1000 ha alana düşen traktör sayısı", "traktör başına düşen tarım alanı", "traktör bașına düșen alet/makina sayısı" ve "ortalama traktör gücü” haritaları oluşturulmuş ve değerlendirilmiştir.

\section{BULGULAR ve TARTISMA}

\section{Birim alana düșen traktör gücü}

Birim alana düşen traktör gücü $\left(\mathrm{kW} \mathrm{ha}{ }^{-1}\right)$ ile ilgili belirlenen sonuçların rakamsal değerleri Çizelge 8'de, grafiksel gösterimleri ve yersel dağılımları ise Şekil 2 ve 3 'de verilmiştir.

Çizelge 8. Türkiye'de birim alana düşen traktör gücü değerleri ( $\left.\mathrm{kW} \mathrm{ha}^{-1}\right)$

\begin{tabular}{lcccccc}
\hline Tarım bölgesi & 2008 & 2009 & 2010 & 2011 & 2012 & 2013 \\
\hline Akdeniz & 1.88 & 1.88 & 1.89 & 2.01 & 2.29 & 2.32 \\
Ege & 2.72 & 2.86 & 2.86 & 2.99 & 3.11 & 3.17 \\
Marmara & $\mathbf{5 . 5 7}$ & $\mathbf{5 . 7 0}$ & $\mathbf{5 . 9 3}$ & $\mathbf{6 . 1 4}$ & $\mathbf{6 . 4 0}$ & $\mathbf{6 . 9 1}$ \\
Batı Anadolu & 1.02 & 1.05 & 1.09 & 1.14 & 1.15 & 1.32 \\
Batı Karadeniz & 2.36 & 2.45 & 2.48 & 2.63 & 2.73 & 2.94 \\
Doğu Karadeniz & $\mathbf{0 . 3 8}$ & $\mathbf{0 . 4 0}$ & $\mathbf{0 . 3 5}$ & $\mathbf{0 . 3 6}$ & $\mathbf{0 . 3 6}$ & $\mathbf{0 . 4 2}$ \\
Orta Anadolu & 1.30 & 1.16 & 1.16 & 1.25 & 1.28 & 1.31 \\
Kuzey Doğu Anadolu & 0.98 & 1.07 & 1.19 & 1.24 & 1.10 & 1.31 \\
Orta Doğu Anadolu & 0.73 & 0.80 & 0.89 & 0.94 & 0.97 & 1.04 \\
Güney Doğu Anadolu & 0.69 & 0.75 & 0.70 & 0.75 & 0.41 & 0.90 \\
\hline Türkiye & 1.98 & 2.03 & 2.18 & 2.14 & 2.18 & 2.37
\end{tabular}




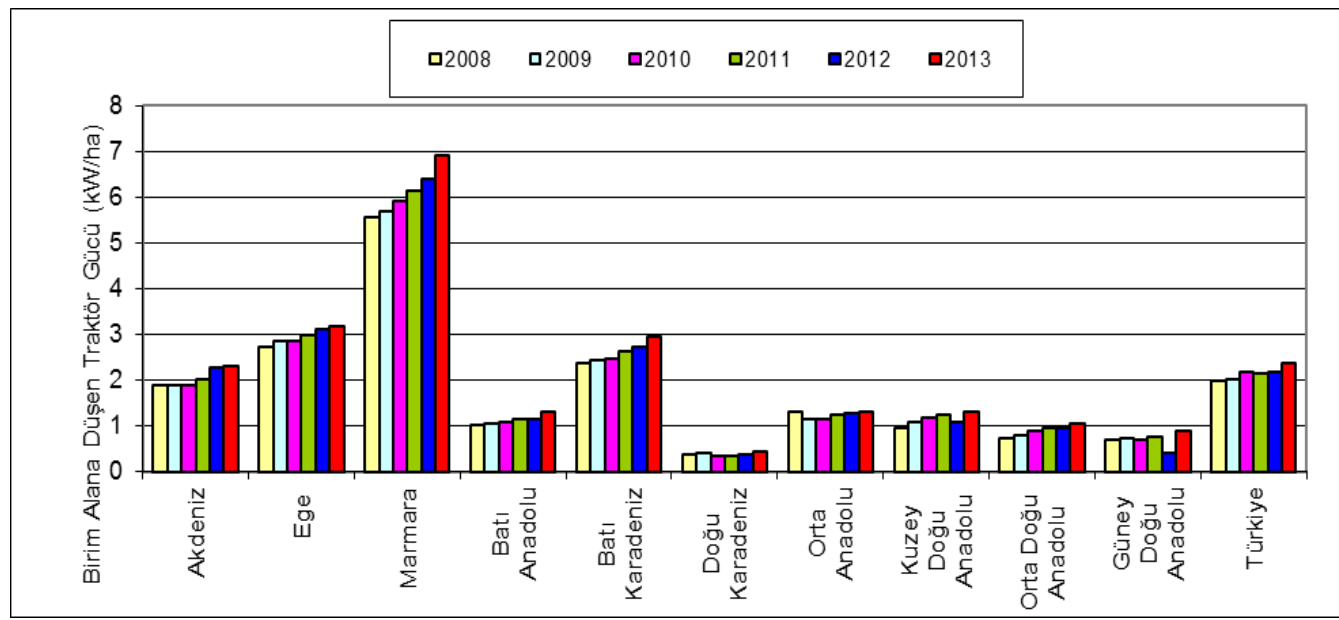

Şekil 2. Türkiye'de birim alana düşen traktör gücünün yıllara ve bölgelere göre grafiksel değişimi


Şekil 3. Türkiye'de birim alana düşen traktör gücünün yıllara (2008-2013) ve bölgelere göre yersel dağılımı

Türkiye'nin tarım bölgelerine göre tarımsal mekanizasyon düzeyi, $\mathrm{kW} \mathrm{ha}^{-1}$ gösterge değeri, 20082013 yıllar itibariyle; genel olarak artmış, en yüksek değerler Marmara en düşük değerler Doğu Karadeniz bölgesinde oluşmuștur. En yüksek değer $6.91 \mathrm{~kW} \mathrm{ha}^{-1}$ ile 2013 yllında Marmara Bölgesinde, en düşük değer ise $0.35 \mathrm{~kW} \mathrm{ha}^{-1}$ ile 2010 yılında Doğu Karadeniz bölgesinde gerçekleşmiştir. Türkiye'nin genel ortalaması ise 1.98-2.37 kW ha ${ }^{-1}$ olmaktadır (Çizelge 8, Şekil 2). Türkiye'nin 2007 yıll için genel tarımsal mekanizasyon düzeyi değeri; Türk Tarım Alet ve Makineleri İmalatçıları Birliği'nin (TARMAKBİR) 
ilgili dönemdeki raporunda (Anonim, 2007) $1.68 \mathrm{~kW}$ $\mathrm{ha}^{-1}$, aynı dönemdeki başka bir araştırmada ise $1.65 \mathrm{~kW}$ ha $^{-1}$ olarak (Dartar, 2007) bildirilmiştir. Birim üretim alanı başına düşen traktör gücü değerlerinin yıllar itibarı ile giderek artması, traktör sayısı ve güç değerlerinin artması ve ayrıca çift çeker traktörlerin kullanımı ile ilişkili olduğu söylenebilir. AB ülkelerinde bu gösterge değeri yaklaşı $6 \mathrm{~kW} \mathrm{ha}^{-1}$ olarak bildirilmektedir (Anonim, 2014). Türkiye'de sadece Marmara Bölgesinin $\mathrm{kW}$ ha ${ }^{-1}$ gösterge değeri, 2011 y1lında $\mathrm{AB}$ ülkelerininkine yakın, 2012-2013 yıllarında ise daha yüksek, diğer bölgelerin ve Türkiye ortalaması ise ele alınan tüm yıllarda, $\mathrm{AB}$ ortalamasından düşük olmaktadır.

Türkiye'de tarım bölgelerinin yıllara ait birim alana düşen traktör gücü $\left(\mathrm{kW} \mathrm{ha}^{-1}\right)$ değerlerine göre 2008 yılında Doğu Karadeniz, Orta Doğu Anadolu ve Güney
Doğu Anadolu bölgeleri 1. grupta (0.38-0.97 kW ha $\left.{ }^{-1}\right)$, Batı Anadolu, Orta Anadolu ve Kuzey Doğu Anadolu bölgeleri 2. grupta (0.98-1.43 kW/ha), Akdeniz bölgesi 3. grupta (1.44-1.89 $\left.\mathrm{kW} \mathrm{ha}{ }^{-1}\right)$, Ege ve Batı Karadeniz bölgeleri 5. grupta $\left(2.36-2.81 \mathrm{~kW} \mathrm{ha}^{-1}\right)$ ve Marmara bölgesi 6. grupta $\left(2.82-5.60 \mathrm{~kW} \mathrm{ha}{ }^{-1}\right)$ yer almaktadır. 2008 yılı ile karşılaştırıldığında; 2013 yılında Akdeniz, Ege ve Batı Karadeniz bölgeleri bulundukları gruplardan bir üst gruba yükselirken diğer bölgelerde değişiklik olmamıştır.

\section{0 ha alana düşen traktör sayısı}

Türkiye'de 2008-2013 yıllarında bölgeler bazında belirlenen, 1000 ha alana düşen traktör sayısı (traktör $1000 \mathrm{ha}^{-1}$ ) değerleri Çizelge 9'da, grafiksel gösterimleri ve yersel dağılımları ise Şekil 4 ve 5'de verilmiştir.

Çizelge 9. Türkiye'de 1000 ha alana düşen traktör sayısı değerleri (traktör $1000 \mathrm{ha}^{-1}$ )



Şekil 4. Türkiye'de 1000 ha alana düşen traktör sayısının yıllara (2008-2013) ve bölgelere göre grafiksel değişimi 



Şekil 5. Türkiye'de 1000 ha alana düşen traktör sayısının bölgelere ve yıllara (2008-2013) göre yersel dağılımı

1000 ha alana düşen traktör sayısı değerleri (traktör 1000 ha $^{-1}$ ); 2008-2013 yillarinda genel olarak hem Türkiye ortalaması hem de bölgeler bazında giderek artmıştır. En yüksek değerler; 2008-2012 yıllarında Ege Bölgesinde (77.97-88.42 traktör $\left.1000 \mathrm{ha}^{-1}\right), 2013$ yılında ise Marmara Bölgesinde (91.69 traktör 1000 ha ${ }^{1}$ ), en düşük değerler ise; tüm yıllar bazında Doğu Karadeniz Bölgesinde (11.12-18.25 traktör $1000 \mathrm{ha}^{-1}$ ) olduğu belirlenmiştir. Türkiye genel ortalaması ise 44.02-52.23 traktör 1000 ha $^{-1}$ olmaktadır (Çizelge 9, Şekil 4). 2007 yllında en düşük değer Güney Doğu Anadolu Bölgesinde (16.3 traktör $1000 \mathrm{ha}^{-1}$ ), en yüksek değer Marmara Bölgesinde (83 traktör 1000 ha $^{-1}$ ) iken (Dartar 2007), 2013 yılında Güney Doğu Anadolu Bölgesinde mekanizasyon düzeyi 30.62 traktör 1000 ha 1 olmuştur.

Türkiye'de tarım bölgelerinin 2008-2013 yıllarına ait, 1000 ha alana düşen traktör sayısı (traktör $1000 \mathrm{ha}^{-1}$ ) yersel değişimlerine (Şekil 5) göre; Akdeniz Bölgesi 2012 yılında, Marmara Bölgesi 2009 ve 2013 yıllarında, Batı Anadolu Bölgesi 2013 yılında, Batı Karadeniz Bölgesi 2011 yılında, Kuzeydoğu Anadolu Bölgesi ise 2013 yllında bir üst gruba yükselirken Orta Anadolu
Bölgesi 2009 yılında bir alt gruba, 2011 y1lında ise bir üst gruba yükselmiştir.

\section{Traktör başına düşen tarım alanı}

Traktör başına düşen tarım alanı değerleri (ha traktör $^{-1}$ ) 2008-2013 yılarında; hem Türkiye geneli hem de bölgeler bazında, genel olarak azalmaktadır (Çizelge 10, Şekil 6). Bu durum genel olarak mekanizasyon düzeyinin arttığını göstermektedir. 2013 yılında Marmara bölgesi 10.91 ha traktör ${ }^{-1}$, Doğu Karadeniz Bölgesi 54.81 ha traktör ${ }^{-1}$, Türkiye geneli 19.15 ha traktör ${ }^{-1}$ olmaktadır.

Türkiye'de tarım bölgelerinin 2008-2013 y1llarına ait, traktör başına düşen tarım alanı (ha traktör ${ }^{-1}$ ) yersel değișimlerine (Şekil 6) göre traktör başına düşen tarım alanı (ha traktör ${ }^{-1}$ ) ölçeğinde; 2008 y1lında, Ege, Marmara ve Batı Karadeniz bölgeleri 1. grupta (12-18 ha traktör $\left.r^{-1}\right)$, Akdeniz bölgesi 2. grupta (19-27 ha traktör $\left.{ }^{-1}\right)$, Orta Anadolu bölgesi 3. grupta (28-36 ha traktör $\left.^{-1}\right)$, Batı Anadolu ve Kuzey Doğu Anadolu bölgeleri 4. grupta (37-45 ha traktör $\left.{ }^{-1}\right)$, Orta Doğu Anadolu bölgesi 5. grupta (46-54 ha traktör ${ }^{-1}$ ) ve Güney Doğu Anadolu bölgesi 6. grupta (55-65 ha traktör $\left.{ }^{-1}\right)$ yer almaktadır. 2008 yılı ile karşılaştırıldığında; 2013 
yılında, Akdeniz, Batı Anadolu, Kuzey Doğu Anadolu, Orta Doğu Anadolu ve Güney Doğu Anadolu bölgeleri

olmamıştır. $\mathrm{Bu}$ düşüş belirtilen bölgelerde bir alt gruba düşerken, diğer bölgelerde değişiklik mekanizasyon seviyesinin iyileștiğinin bir ifadesidir.

Çizelge 10. Türkiye'de traktör başına düşen tarım alanı değerleri (ha traktör ${ }^{-1}$ )

\begin{tabular}{lcccccc}
\hline Tarım bölgesi & 2008 & 2009 & 2010 & 2011 & 2012 & 2013 \\
\hline Akdeniz & 18.86 & 18.89 & 18.68 & 17.49 & 15.63 & 15.46 \\
Ege & $\mathbf{1 2 . 8 3}$ & $\mathbf{1 2 . 3 0}$ & $\mathbf{1 2 . 3 1}$ & $\mathbf{1 1 . 7 4}$ & $\mathbf{1 1 . 3 1}$ & 11.16 \\
Marmara & 13.37 & 13.05 & 12.60 & 12.14 & 11.67 & $\mathbf{1 0 . 9 1}$ \\
Batı Anadolu & 39.48 & 38.61 & 37.28 & 35.54 & 35.82 & 31.79 \\
Batı Karadeniz & 14.76 & 14.29 & 14.20 & 13.19 & 12.70 & 12.00 \\
Doğu Karadeniz & $\mathbf{6 4 . 7 3}$ & $\mathbf{7 8 . 4 6}$ & $\mathbf{8 9 . 9 3}$ & $\mathbf{7 2 . 1 2}$ & $\mathbf{6 7 . 1 5}$ & $\mathbf{5 4 . 8 1}$ \\
Orta Anadolu & 29.71 & 33.38 & 33.62 & 31.11 & 30.45 & 30.07 \\
Kuzey Doğu Anadolu & 42.96 & 39.20 & 35.75 & 34.40 & 38.88 & 32.66 \\
Orta Doğu Anadolu & 49.44 & 44.91 & 42.53 & 39.80 & 38.60 & 36.32 \\
Güney Doğu Anadolu & 58.89 & 53.34 & 57.29 & 53.16 & 47.25 & 44.31 \\
\hline Türkiye & 22.71 & 22.26 & 22.27 & 20.99 & 20.19 & 19.15 \\
\hline
\end{tabular}

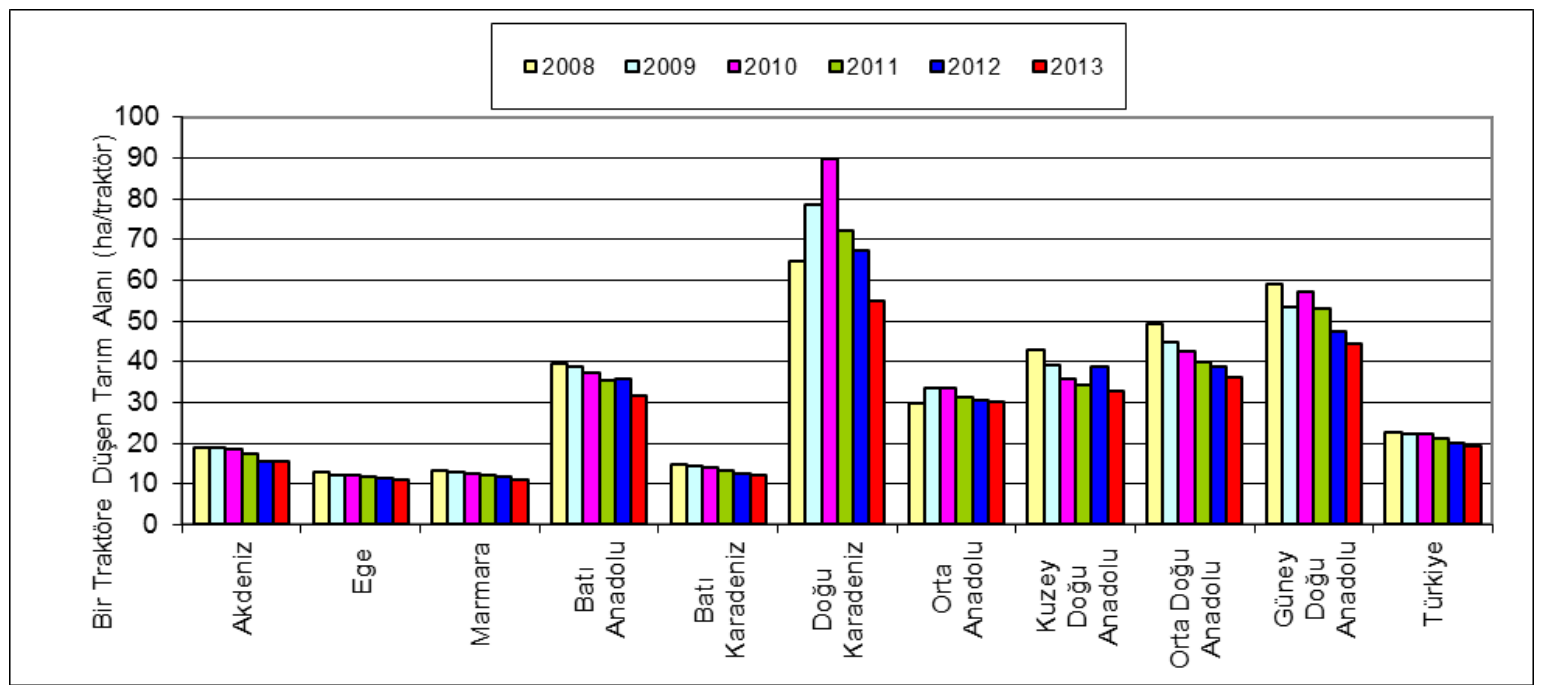

Şekil 6. Türkiye'de traktör başına düşen tarım alanının yıllara (2008-2013) ve bölgelere göre grafiksel değişimi

Traktör başına düșen alet/makina sayısı

Traktör başına düşen tarım alet/makina (alet/makina traktör ${ }^{-1}$ ) değerleri, 2008-2013 yılarında; hem Türkiye geneli hem de bölgeler bazında, genel olarak değişiklik göstermektedir. Doğu Karadeniz Bölgesinde en yüksek
(7.83-12.90 alet/makina traktör ${ }^{-1}$ ) ve Batı Karadeniz Bölgesinde ise en düşük (4.24-4.61 alet/makina traktör ${ }^{-}$ $\left.{ }^{1}\right)$ olmaktadır. Türkiye genelinde ise 4.79-5.32 alet/makina traktör ${ }^{-1}$ değerleri belirlenmiştir (Çizelge 11, Şekil 8).

Çizelge 11. Türkiye'de traktör başına düşen alet/makina sayısı değerleri (alet/makina traktör ${ }^{-1}$ )

\begin{tabular}{lcccccc}
\hline Tarım bölgesi & 2008 & 2009 & 2010 & 2011 & 2012 & 2013 \\
\hline Akdeniz & 4.77 & 4.66 & 5.01 & 4.81 & 4.78 & 4.73 \\
Ege & 5.18 & 5.18 & 5.14 & 5.11 & 4.56 & 4.88 \\
Marmara & 5.55 & 5.57 & 5.61 & 3.10 & 5.38 & 5.33 \\
Batı Anadolu & 6.09 & 6.24 & 6.36 & 6.38 & 6.57 & 5.73 \\
Batı Karadeniz & $\mathbf{4 . 6 1}$ & $\mathbf{4 . 6 0}$ & $\mathbf{4 . 6 5}$ & $\mathbf{4 . 5 9}$ & $\mathbf{4 . 3 6}$ & $\mathbf{4 . 2 4}$ \\
Doğu Karadeniz & $\mathbf{7 . 8 3}$ & $\mathbf{1 2 . 9 0}$ & $\mathbf{1 1 . 4 5}$ & $\mathbf{9 . 7 5}$ & $\mathbf{8 . 9 2}$ & $\mathbf{7 . 9 5}$ \\
Orta Anadolu & 5.19 & 5.39 & 5.48 & 5.42 & 5.39 & 5.51 \\
Kuzey Doğu Anadolu & 5.52 & 5.47 & 5.48 & 5.44 & 5.44 & 5.44 \\
Orta Doğu Anadolu & 6.14 & 6.13 & 5.73 & 5.61 & 5.51 & 5.19 \\
Güney Doğu Anadolu & 5.19 & 5.14 & 5.43 & 5.53 & 5.34 & 5.37 \\
\hline Türkiye & 5.28 & 5.32 & 5.01 & 4.79 & 5.12 & 5.09 \\
\hline
\end{tabular}





Bir Traktöre Düşen

Tarım Alanı

ha/Traktör

$10-18$

$19-27$

$28-36$

$37-45$

$46-54$

$55-68$

Şekil 7. Türkiye'de traktör başına düşen tarım alanı değerlerinin bölgelere ve yıllara (2008-2013) göre yersel dağılımı

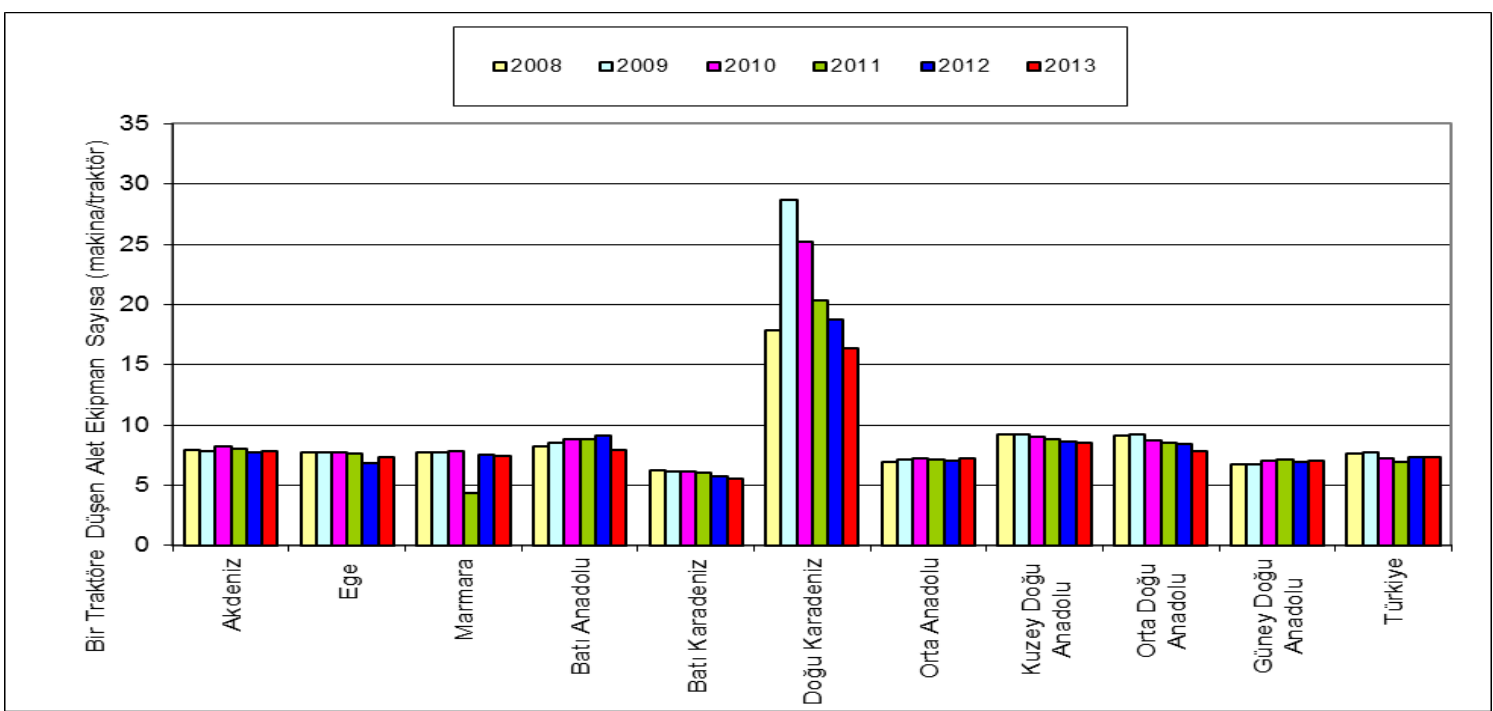

Şekil 8. Türkiye'de traktör başına düşen alet-makina sayısının yıllara (2008-2013) ve bölgelere göre grafiksel değişimi

Traktör başına düşen alet/makina sayısı (alet/makina traktör ${ }^{-1}$ ) değerlerinin yersel değișimlerine (Şekil 9) göre traktör başına düşen alet/makine sayısı (alet/makina traktör ${ }^{-1}$ ) ölçeğinde; 2008 yılında, Akdeniz, Ege, Batı Karadeniz, Orta Anadolu ve Güney Doğu Anadolu bölgeleri 1. grupta (4.0-5.5 alet/makina traktör ${ }^{-}$ 
${ }^{1}$ ), Marmara, Batı Anadolu, Kuzey Doğu Anadolu ve Orta Doğu Anadolu bölgeleri 2. grupta (5.6-7.1 alet/makina traktör ${ }^{-1}$ ) ve Doğu Karadeniz bölgesi ise 3 . grupta (7.2-8.7 alet/makina traktör ${ }^{-1}$ ) yer almaktadır. 2008 yılı ile karşılaştırıldığında; 2013 yılında, Orta Anadolu bölgesi bir üst gruba yükselirken, Marmara, Kuzey Doğu Anadolu ve Orta Doğu Anadolu bölgeleri bir alt gruba düşmüş, diğer bölgelerde değişiklik olmamıştır.

\section{Ortalama traktör gücü}

Türkiye'de 2008-2013 y1llarında bölgeler bazında belirlenen, ortalama traktör gücü $(\mathrm{kW})$ değerleri Çizelge 12 'de, grafiksel gösterimleri ve yersel dağılımlarına ait haritalar ise Şekil 10 ve 11 'de verilmiştir.
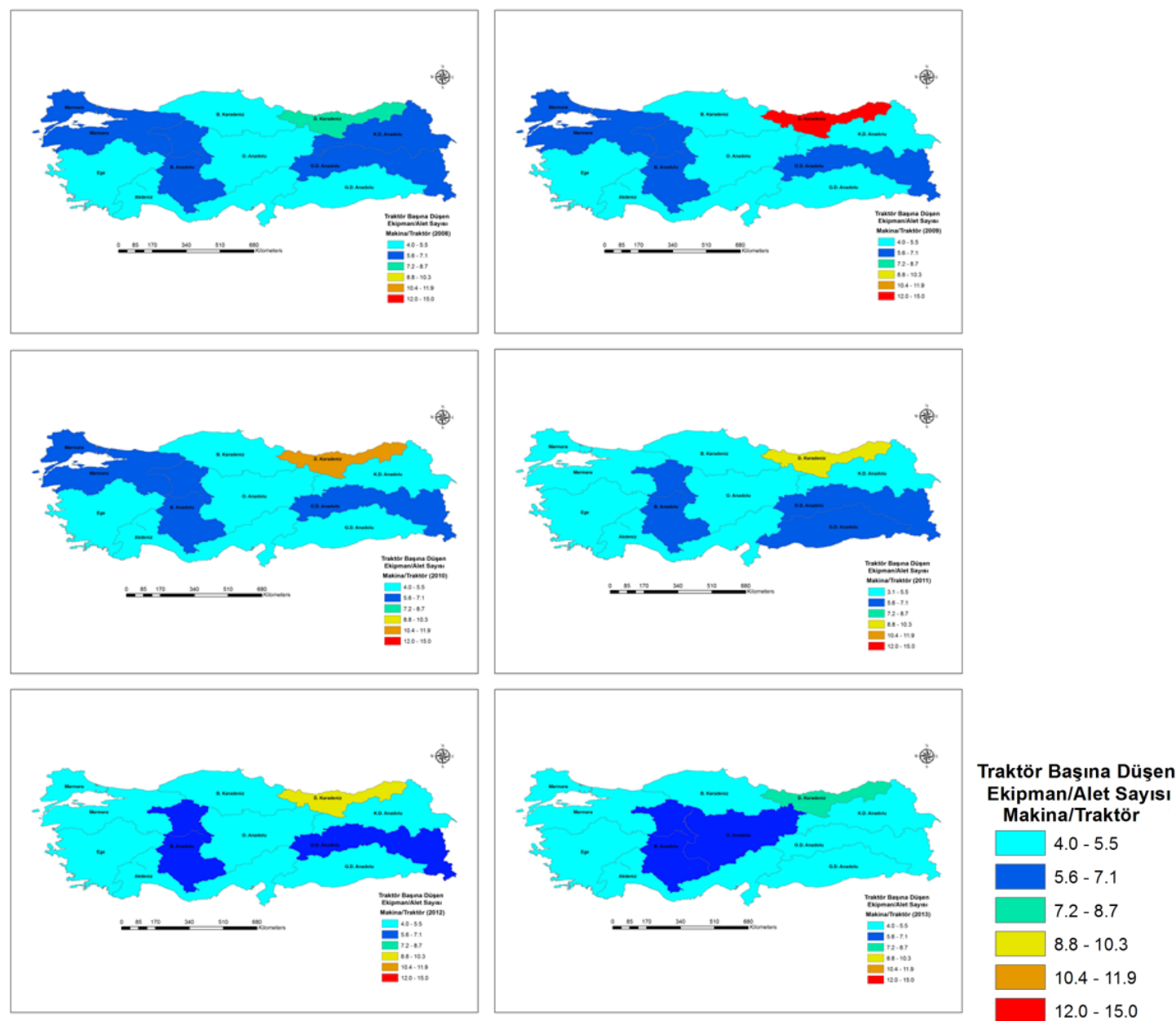

Şekil 9. Türkiye'de traktör başına düşen alet/makina sayısının bölgelere ve yıllara (2008-2013) göre yersel dağılımı

Çizelge 12. Türkiye'de ortalama traktör gücü değerleri $(\mathrm{kW})$

\begin{tabular}{lcccccc}
\hline Tarım bölgesi & 2008 & 2009 & 2010 & 2011 & 2012 & 2013 \\
\hline Akdeniz & 35.53 & 35.53 & 35.38 & 35.20 & 35.79 & 35.88 \\
Ege & 34.92 & 35.17 & 35.21 & 35.11 & 35.22 & 35.37 \\
Marmara & $\mathbf{7 4 . 5 4}$ & $\mathbf{7 4 . 3 7}$ & $\mathbf{7 4 . 7 2}$ & $\mathbf{7 4 . 5 1}$ & $\mathbf{7 4 . 7 3}$ & $\mathbf{7 5 . 3 4}$ \\
Batı Anadolu & 40.27 & 40.54 & 40.54 & 40.55 & 41.06 & 42.08 \\
Bat1 Karadeniz & 34.83 & 35.05 & 35.20 & 34.67 & 34.67 & 35.27 \\
Doğu Karadeniz & $\mathbf{2 4 . 3 9}$ & $\mathbf{3 1 . 7 6}$ & $\mathbf{3 1 . 2 4}$ & $\mathbf{2 5 . 6 5}$ & $\mathbf{2 4 . 3 9}$ & $\mathbf{2 3 . 2 7}$ \\
Orta Anadolu & 38.62 & 38.67 & 38.87 & 38.78 & 38.95 & 39.29 \\
Kuzey Doğu Anadolu & 41.67 & 42.10 & 42.70 & 42.55 & 42.66 & 42.81 \\
Orta Doğu Anadolu & 36.00 & 35.81 & 37.86 & 37.48 & 37.33 & 37.84 \\
Güney Doğu Anadolu & 40.75 & 39.75 & 39.91 & 39.85 & 39.54 & 40.04 \\
\hline Türkiye & 45.06 & 45.17 & 43.97 & 44.99 & 43.97 & 45.30 \\
\hline
\end{tabular}




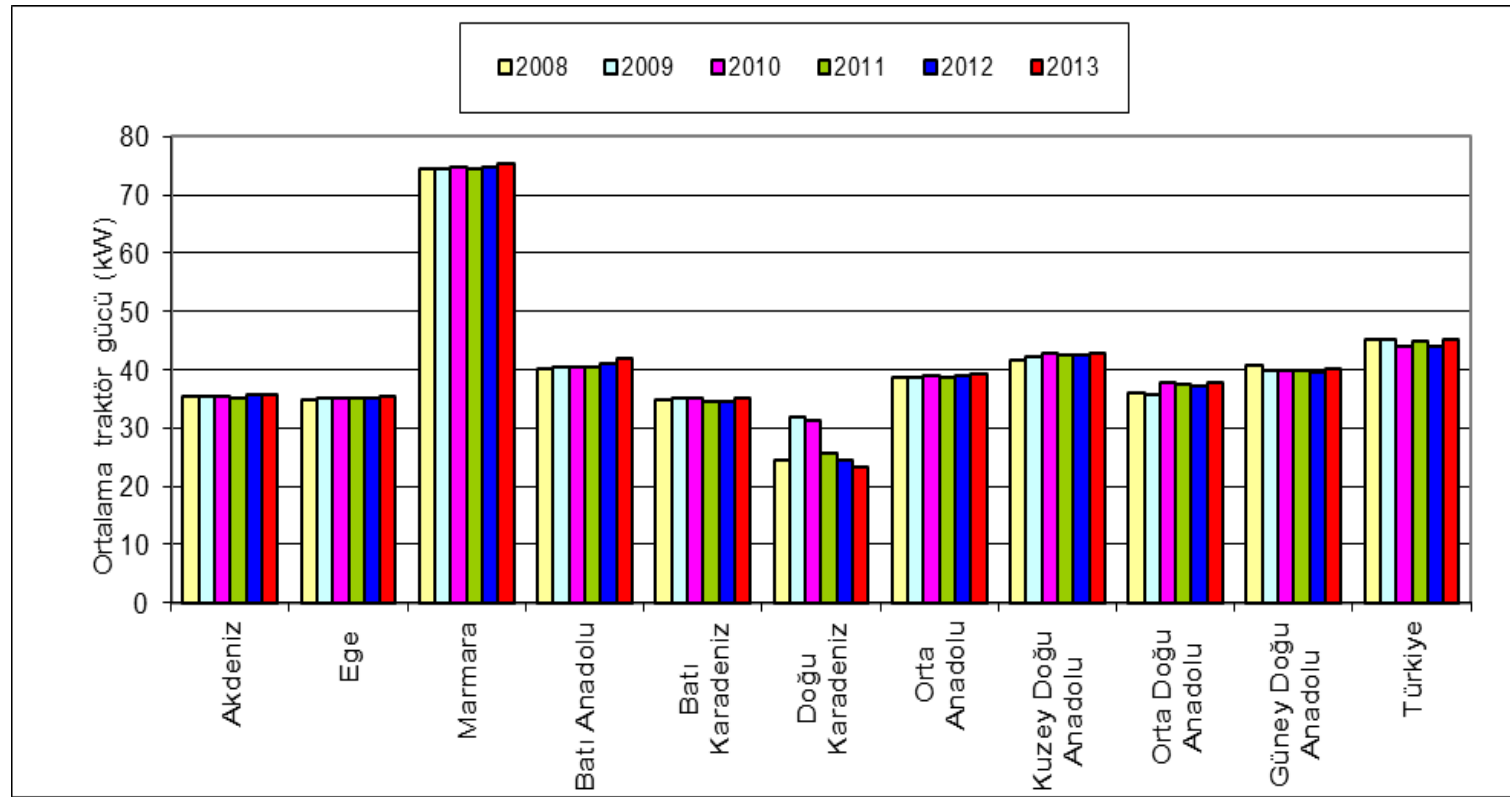

Şekil 10. Türkiye'de ortalama traktör gücünün yıllara (2008-2013) ve bölgelere göre grafiksel değişimi
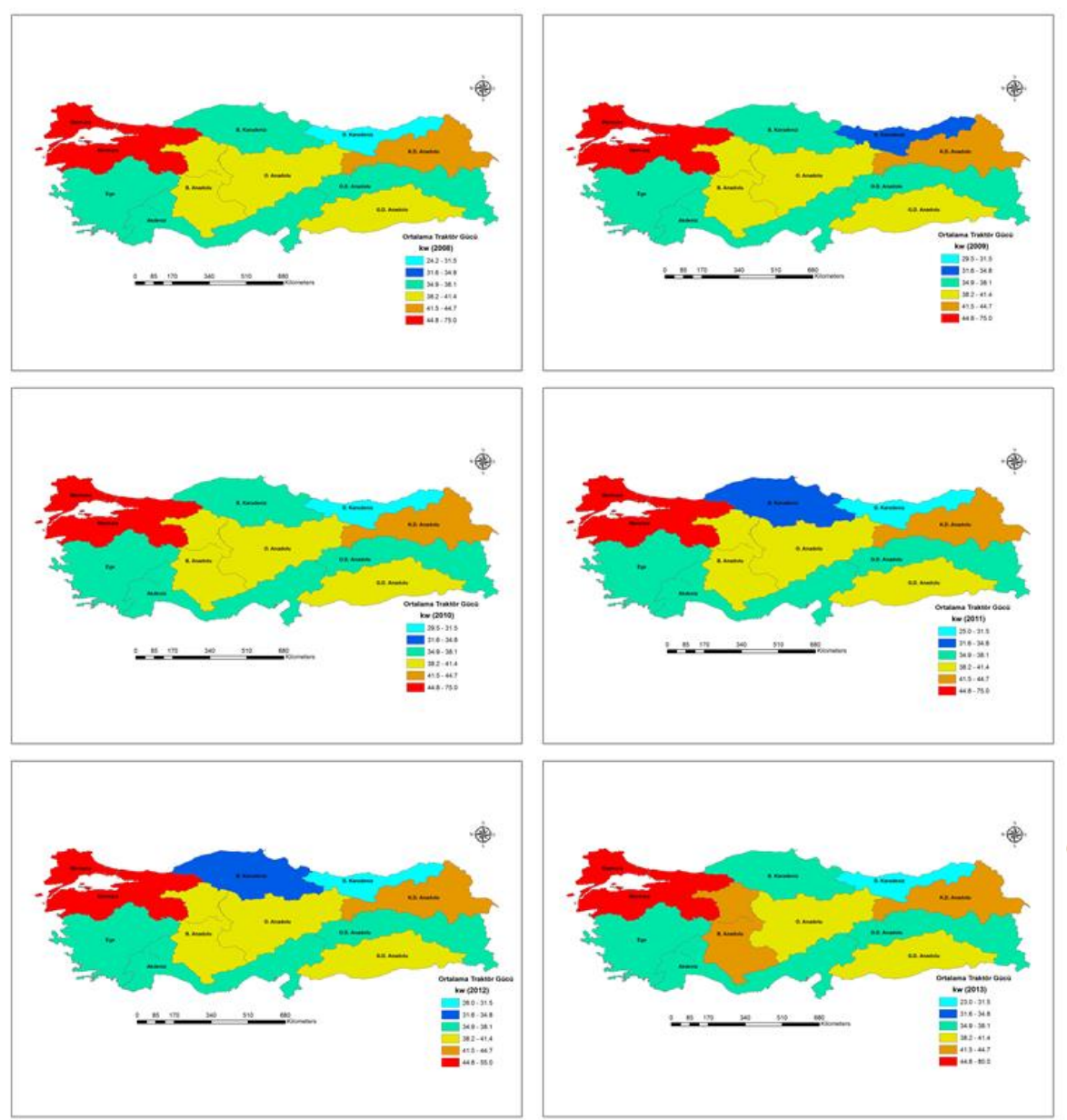

Ortalama Traktör Gücü

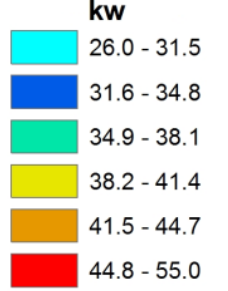

Şekil 11. Türkiye'de ortalama traktör gücü değerlerinin bölgelere ve yıllara (2008-2013) göre yersel dağılımı

Ortalama traktör gücü $(\mathrm{kW}), 2008-2013$ yillarında en yüksek değer Marmara Bölgesinde (74-75 kW), en düşük değer Doğu Karadeniz Bölgesinde (23-32 kW) olduğu belirlenmiştir. Türkiye genelinde ise bu değer
44-45 kW arasında değişmiştir (Çizelge 12, Şekil 10). Ortalama traktör gücü değerlerinin Marmara Bölgesinde yüksek olması yörede çift çeker traktörlerin daha fazla kullanım oranıyla ilişkili olduğu söylenebilir. 
Türkiye'de tarım bölgelerinin 2008-2013 y1llarına ait, ortalama traktör gücü $(\mathrm{kW})$ değerlerinin yersel değişimlerine (Şekil 11) göre ortalama traktör gücü (kW) ölçeğinde; 2008 yılında Doğu Karadeniz bölgesi 1. grupta (24.2-31.5 kW), Akdeniz, Ege, Batı Karadeniz ve Orta Doğu Anadolu bölgeleri 3. grupta (34.9-38.1 kW), Batı Anadolu, Orta Anadolu ve Güney Doğu Anadolu bölgeleri 4. grupta (38.2-41.4 kW), Kuzey Doğu Anadolu bölgesi 5. grupta (41.5-44.7), Marmara bölgesi ise 6 . grupta $(44.8-75 \mathrm{~kW})$ yer almaktadır. 2008 yılı ile karşılastırıldığında; 2013 yılında, Batı Anadolu bölgesi bir üst gruba yükselirken, diğer bölgelerde bir değişiklik olmamıştır.

\section{SONUÇLAR}

Tarım işletmelerinde, tarımsal mekanizasyon girdisi üretim verimliliği üzerinde önemli bir etkiye sahiptir. Gelişmiş ülkelerde işletmelerin makine parkı ve işletilmesi bilimsel esaslara dayalı olarak yapılmaktadır. $\mathrm{Bu}$ nedenle ulusal ölçekli planlamalar için tarımsal mekanizasyon düzeyi göstergelerinin mevcut verilerle değerlendirilmesi gerekmektedir.

$\mathrm{Bu}$ çalışmada; 2014 TUIK verileri kullanılarak, 2008-2013 yıllarında Türkiye'nin Tarım Bölgeleri bazında ve genelinde tarımsal mekanizasyon düzeyi gösterge değerleri $\left(\mathrm{kW} \mathrm{ha-1}\right.$, traktör $1000 \mathrm{ha}^{-1}$, ha traktör ${ }^{-1}$, alet/makine traktör $\mathrm{r}^{-1}, \mathrm{~kW}$ ) belirlenmiş, yersel değişim haritaları ve grupları oluşturulmuş ve değerlendirilmiştir.

Türkiye'nin tarımsal mekanizasyon düzeyi, hem genel hem de bölgelere göre, ele alınan yıllar itibariyle genel olarak artmıștır.

kW ha ${ }^{-1}$ gösterge değeri; en yüksek Marmara (6.91) en düşük Doğu Karadeniz Bölgesinde (0.35) belirlenmiştir. Türkiye'nin genel ortalaması ise 1.98$2.37 \mathrm{~kW} \mathrm{ha}{ }^{-1}$ olmaktadır. Oluşturulan yersel değişim haritalarına göre, $\mathrm{kW} \mathrm{ha}{ }^{-1}$ değerleri; Ege Bölgesinde 2008-2009 yıllarında Marmara Bölgesine, Akdeniz Bölgesinde 2010-2011 yıllarında Batı Karadeniz Bölgesine, Batı Karadeniz Bölgesinde 2012-2013 yıllarında Marmara Bölgesine yaklaşmıştır.

Traktör $1000 \mathrm{ha}^{-1}$ gösterge değeri; en yüksek Marmara Bölgesinde (91.69) ve en düşük Doğu Karadeniz Bölgesinde (11.12) belirlenmiştir. Türkiye genel ortalamas1 ise 44.02-52.23 traktör $1000 \mathrm{ha}^{-1}$ arasında olmuştur. Yersel değişim haritalarına göre traktör 1000 ha $^{-1}$ ölçeğinde; Batı ve Doğu Karadeniz bölgeleri 2011 yılında, Akdeniz bölgesi 2012 yılında, Kuzeydoğu Anadolu Bölgesi ise 2013 yılında Marmara Bölgesine yaklaşmıştır.

ha traktör ${ }^{-1}$ gösterge değeri; Marmara bölgesinde 10.9, Doğu Karadeniz Bölgesinde 54, Türkiye genelinde ise 19.15 olarak belirlenmiştir. Türkiye geneli ise 19.15 ha traktör ${ }^{-1}$ olmuştur. Yersel değişim haritalarına göre ha traktör ${ }^{-1}$ ölçeğinde; Güney Doğu Anadolu Bölgesi 2010 yılında, Kuzey Doğu Anadolu Bölgesi ise 2012 yıllında Marmara Bölgesine yaklaşmıştır.
Alet/makina traktör ${ }^{-1}$ gösterge değerleri, en yüksek Doğu Karadeniz Bölgesinde (7.83-12.90), en düşük Batı Karadeniz Bölgesinde (4.24-4.61) saptanmıştır. Türkiye genelinde ise 4.79-5.32 alet/makina traktör ${ }^{-1}$ değerleri belirlenmiştir. Yersel değişim haritalarına göre alet/makina traktör ${ }^{-1}$ ölçeğinde; Doğu Karadeniz Bölgesi 2009 yılında, Güney Doğu Anadolu Bölgesi 2011 yılında ve Orta Anadolu Bölgesi ise 2013 yılında Marmara Bölgesine yaklaşmıştır.

kW gösterge değeri; en yüksek Marmara Bölgesinde (74-75 kW), en düşük Doğu Karadeniz Bölgesinde (23$32 \mathrm{~kW}$ ) belirlenmiştir. Türkiye genelinde ise $44-45 \mathrm{~kW}$ değeri elde edilmiştir. Yersel değişim haritalarına göre ortalama traktör gücü (kW) ölçeğinde; Doğu Karadeniz Bölgesi 2009 yılında, Batı Anadolu ve Batı Karadeniz Bölgeleri ise 2013 yılında Marmara Bölgesine yaklaşmıştır.

\section{KAYNAKLAR}

Anonim, 2000. Tarım alet ve makinaları sanayii ve rekabet edebilirlik özel ihtisas komisyonu raporu (Sekizinci Beş Yıllık Kalkınma Planı). TC Başbakanlık Devlet Planlama Teşkilatı, Ankara.

Anonim, 2007. TARMAKBİR sektör raporu. Türk Tarım Alet ve Makineleri İmalatçıları Birliği Yayını.

Anonim, 2014. TARMAKBİR sektör raporu. Türk Tarım Alet ve Makineleri İmalatçıları Birliği Yayını (http://www.tarmakbir.org/haberler/tarmakbirsekrap. pdf)

Akıncı, İ., Topakçı, M., Çanakçı, M. 1997. Antalya bölgesi tarım işletmelerinin tarımsal yapı ve mekanizasyon özellikleri. Tarımsal Mekanizasyon 17. Ulusal Kongresi, 17-19 Eylül 1997,Tokat, s. 4558.

Dartar, İ. 2007. Türkiye'nin tarımsal mekanizasyon düzeyinin değerlendirilmesi ve coğrafi bilgi sistemleri ile haritalanması. Yüksek Lisans Tezi, Çukurova Ünivertsitesi Fen Bilimleri Enstitüsü, Tarım Makinaları ABD, Adana.

Ergüneş, G., Tarhan, S., Yardım, M. H., Kasap, A., Demir, F., Önal, İ., Uçar, T., Tekelioğlu, O., Çalışır, S., Yumak, H., Yağcıoğlu, A. 2009. Tarım Makinaları. Nobel Bilim ve Araştırma Merkezi, Yayın No:49, Ankara, s. 544.

Evcim, H.Ü., Ulusoy, E., Gülsoylu, E., Tekin, B. 2010. Tarımsal mekanizasyon durumu sorunları ve çözüm önerileri. Türkiye Ziraat Mühendisleri 7. Teknik Kongresi Bildiriler Kitab1-2, Ankara s. 989-1007.

Landers, A. 2000. Resource management: farm machinery/selection, investment and management. Farming Press, United Kingdom, pp. 151.

Sabanc1, A., Akınc1, İ. 1994. Dünyada ve Türkiye'de tarımsal mekanizasyon düzeyi ve son gelişmeler. Tarımsal Mekanizasyon 15. Ulusal Kongresi, 20-22 Eylül 1994, Antalya, s. 404-415.

Say, S. M., Sabancı, A., Başçetinçelik, A., Özgüven, F., Öztürk, H.H. 2010. Tarım Makinaları 1. Nobel 
Kitabevi Yayın Dağıtım ve Pazarlama Ltd. Şti. Adana.

Ruiyin, H., Wenqingv, Y., Yadong, Z., Van Sonsbeek, G. 1999. Improving management system of agricultural machinery in jiangsu. Proceedings of 99 International Conference on Agri. Engine, Beijing, China, pp. I-42-45
TUIK. 2014. Türkiye İstatistik Kurumu. Tarımsal İstatistik Verileri, Ankara. http://www.tuik.gov.tr (Erişim tarihi: Mayıs 2014).

Zeren, Y., Tezer, E., Tuncer, İ.K., Evcim, Ü., Güzel, E., Sindır, K.O. 1995. Tarım Alet-Makine ve Ekipman Kullanım ve Üretim Sorunları. Ziraat Mühendisliği Teknik Kongresi Tarım Haftası 95 Kongresi, 9-13 Ocak 1995, Ankara. 